\title{
A PROSPECTIVE, RANDOMIZED STUDY USING TRANSDERMAL ELECTROMOTIVE ADMINISTRATION OF VERAPAMIL AND DEXAMETHASONE FOR PEYRONIE'S DISEASE
}

\author{
SAVINO M. DI STASI, $* \dagger$ ANTONELLA GIANNANTONI, $\dagger$ ROBERT L. STEPHEN \\ GIOVANNI CAPELLI, $\dagger$ ARCANGELO GIURIOLI, $\dagger$ EMMANUELE A. JANNINI $\dagger$ AND \\ GIUSEPPE VESPASIANI $\dagger$
}

\begin{abstract}
From the Department of Urology, Tor Vergata University, Rome, Department of Urology, University of Perugia, Perugia, Physion Laboratories, Medolla, Department of Science and Society, University of Cassino, Cassino, Department of Experimental Medicine, University of L'Aquila, L'Aquila, and Operative Unit of Urology, “Antonio Perrino” Hospital, Brindisi, Italy
\end{abstract}

\section{ABSTRACT}

Purpose: Uncontrolled studies with intraplaque electromotive administration of verapamil and dexamethasone have demonstrated objective improvements in Peyronie's disease. We performed a prospective controlled study to assess the efficacy of intraplaque electromotive verapamil/ dexamethasone vs electromotive lidocaine.

Materials and Methods: Patients with Peyronie's disease were randomized into a study group (47 patients) and a control group (49 patients). For each treatment session an electrode receptacle was sited over the plaque and filled with either $5 \mathrm{mg}$ verapamil and $8 \mathrm{mg}$ dexamethasone (study group) or $2 \%$ lidocaine (control group), and a $2.4 \mathrm{~mA}$ electric current was applied for 20 minutes. All patients were scheduled for 4 sessions per week for 6 weeks. Assessment before and after treatment included measurements of plaque volume and penile curvature, and pain on erection (from questionnaire).

Results: A total of 37 patients in the study group and 36 in the control group completed treatment courses. In the study group there were significant decreases in median plaque volume from 824 to $348 \mathrm{~mm}^{3}$, and in penile curvature from 43 to 21 degrees. In the control group median volume and curvature were unchanged. The difference in results after treatment between the 2 groups was also significant. Significant pain relief occurred in both groups, transient in the control group and permanent in the study group. All patients experienced temporary erythema at the electrode site. There were no other side effects.

Conclusions: Intraplaque electromotive verapamil and dexamethasone induce substantial objective improvement in Peyronie's disease compared to electromotive lidocaine administration.

KEY WoRDS: penile induration, verapamil, dexamethasone, electricity

Until recently Peyronie's disease was relegated to an obscure niche in urology, a surprising state of affairs because there are estimates that $3 \%$ to $5 \%$ of men are affected and pain is a prominent symptom. Now the situation has changed and most major urological meetings devote special sessions to Peyronie's disease and have increasing attendance. It is tempting to ascribe a catalytic role to sildenafil. Release of this drug in 1996 diminished many inhibitions and previously reticent patients now seek medical help.

In spite of renewed interest, the etiology and pathophysiology of Peyronie's disease are still unclear. The pathology is strongly indicative of abnormal wound healing giving rise to fibrosis within the tunica albuginea ${ }^{1}$ and the large number of treatments currently available attests to the fact that none is uniformly successful. ${ }^{2}$ Surgical correction of the deformity

Accepted for publication October 24, 2003

Supported by grants Progetti di Ricerca di Ateneo (ex 60\%) 2001 from Tor Vergata University of Rome.

Study received institutional review board approval.

* Correspondence: Via Torrice n. 4, 00189 Rome, Italy (telephone: 390630311655; FAX: 390623188353; e-mail: sdistas@tin.it).

$\dagger$ Nothing to disclose.

$\$$ Financial interest and/or other relationship with Physion Srl.

Editor's Note: This article is the fourth of 5 published in this issue for which category 1 CME credits can be earned. Instructions for obtaining credits are given with the questions on pages 1670 and 1671 . should be the answer in most cases but it is not a minor procedure and adequate illustration causes a substantial proportion of patients to refuse surgery. There is also the problem of either an ongoing or recurrent disease process leading to treatment failure. Systemic drug administration frequently results in more side effects than therapeutic benefit.

Localized drug administration directly into and around the plaque provides high concentrations at the site of disease with minimal systemic effects. In a large uncontrolled clinical study Levine et al demonstrated significant improvement in patients after intralesional injection of verapamil. ${ }^{3}$ However, multiple intralesional injections may be uncomfortable and, rarely, may cause harm. Transdermal diffusive drug delivery has been used sporadically but a recent report described application of verapamil cream and no detectable levels of the drug in the underlying tunica. ${ }^{4}$ Conversely, transdermal electromotive administration of verapamil resulted in detectable tunica levels in approximately $70 \%$ of specimens tested. ${ }^{5}$ Furthermore, 3 clinical studies with different drug and treatment regimens using electromotive delivery of verapamil in combination with dexamethasone demonstrated objective improvement in patients with Peyronie's disease. ${ }^{6-8}$ We now report on a prospective, controlled investigation of patients with Peyronie's disease using electromotive administration of verapamil and dexamethasone vs electromotive administration of lidocaine in a control group. 


\section{MATERIALS AND METHODS}

Patient selection. From January 2001 to December 2002, 96 patients were enrolled in the study. Inclusion criteria were clinical evidence of primary Peyronie's disease including plaque, deformity of the penis and pain on erection or nonspecific genital pain. Exclusion criteria were recent treatment with calcium channel blockers or corticosteroids, therapies interfering with these 2 drugs, and erectile dysfunction due to causes other than Peyronie's disease as assessed by psychological, vascular, hormonal and neurological evaluation.

Study design. The institutional review boards of the individual centers participating in the trial approved this prospective, randomized double blind study. The patients were informed about the scientific nature of the investigation and supplied written informed consent. The subjects were allocated to 1 of 2 groups (see figure) those treated with intraplaque electromotive administration of lidocaine (control group), and those treated with electromotive administration of verapamil and dexamethasone (study group).

Evaluation. The reliability of objective measurements of plaque size, penile deviation and subjective score scales of a questionnaire provided to patients were determined by a test-retest multicenter pilot study. ${ }^{8}$ Clinical assessment and objective measurements were performed before and 4 weeks after the conclusion of treatment. Duplex ultrasound examinations using a $7.5 \mathrm{MHz}$ transducer were performed in the state of maximum pharmacologically induced erection using an intracavernosal injection of $20 \mu \mathrm{g}$ prostaglandin E1. Plaque stage, fibrous or calcified, was evaluated with ultrasound and plain x-rays. Plaque length was determined by calipers and duplex ultrasound, and volume was calculated from length, width and depth. Penile deviation and the localization of the angle were assessed by photography of the penis at maximum pharmacologically induced erection in 3 planes following Kelâmi's criteria. ${ }^{9}$ The subjective symptom, pain, was evaluated by a questionnaire using a 3 -step ordinal descriptive scale (none, mild, moderate).

Treatment regimen. Randomization and data collection were performed using a central computer and patients were allocated to 1 of 2 treatment arms with blocked randomization across $4(2 \times 2)$ strata resulting from 2 factors, plaque volume $1,000 \mathrm{~mm}^{3}$ or less versus plaque volume greater than $1,000 \mathrm{~mm}^{3}$, and penile curvature 35 degrees or less versus penile curvature greater than 35 degrees, which ensured parity between control and study groups.

The treatment plan included 4 sessions per week for 6 consecutive weeks. During each session a $5 \mathrm{ml}$ adhesive

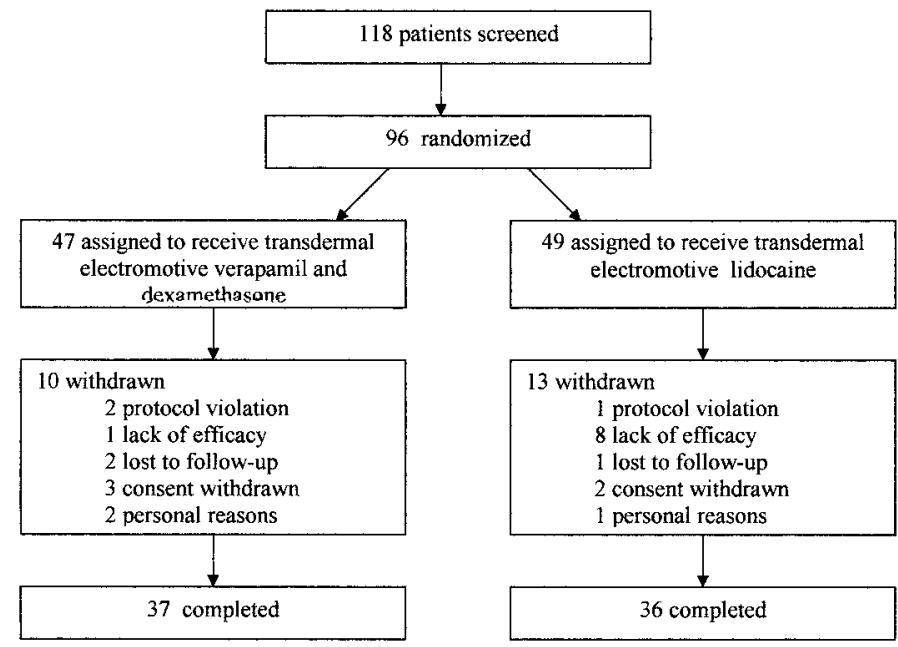

Trial flow diagram incorporating patient numbers and status to completion of study. electrode receptacle (CT-DAS $500 \mathrm{Ag}$, Physion s.r.l, Medolla, MO, Italy) was fixed to the penile skin overlying the plaque. The receptacle was filled with either $8 \mathrm{mg}$ dexamethasone and $5 \mathrm{mg}$ verapamil diluted to a $5 \mathrm{ml}$ volume with water (study group) or $5 \mathrm{ml} \mathrm{2 \%}$ lidocaine (control group). The anode was connected to the receptacle and the cathode connected to a skin electrode which was placed on the lower abdomen. A current generator (Physionizer 30, Physion s.r.l) provided pulsed direct current of $2.4 \mathrm{~mA}$ at $2,500 \mathrm{~Hz}$ for 20 minutes. Blood pressure and heart rate were monitored throughout the procedure and after each session. The incidence of systemic, local, acute and chronic toxicity was recorded.

Statistical analysis. Summarized results for continuous data (plaque size and penile deviation) are presented as medians and interquartile ranges (IQR, the difference between 1st quartile and 3rd quartile, which comprises the middle $50 \%$ of the data). Univariate differences in continuous and ordinal scale data (pain) measured before and after treatment were assessed in each group separately by the paired Wilcoxon signed rank test. The difference between treatment groups was assessed by the unpaired MannWhitney-Wilcoxon rank sum test performed on before and after differences. To evaluate the effect of pretreatment disease severity (plaque volume, penile deviation and pain at rest), Fisher's exact test for contingency table was used.

\section{RESULTS}

Of 118 patients screened 96 were randomized and a total of 73 completed the study, 36 in the control group and 37 in the study group (see figure). The pertinent characteristics of patients in the 2 groups were comparable (table 1).

Evaluation before and after treatment. Table 2 shows the results of treatments in both groups with respect to plaque volume, penile deviation and pain during erection. Within the control group there were no significant differences in plaque volume and penile deviation before and after therapy. Conversely, both characteristics were significantly decreased in the study group and the differences between groups after treatment were also significant.

In the control group plaque volume increased or was unchanged in 15 patients ( $42 \%$ ) and decreased by less than $50 \%$ in 21 patients (58\%). In the study group plaques resolved completely in 5 patients (14\%), were decreased by more than $50 \%$ in 20 patients (54\%) and decreased by less than $50 \%$ in 12 patients $(32 \%)$.

In the control group penile deviation was unchanged or increased in 32 patients $(89 \%)$ and no patient achieved a decrease of 15 degrees or more. In the study group the deviation resolved completely in 5 patients $(14 \%)$ and decreased by more than 20 degrees in another 16 patients (43\%). Furthermore, within this same group patients with narrowing, indentation or hourglass deformities demonstrated similar degrees of improvement.

Significant relief of pain on erection followed treatments in both groups but there was an important difference. Pain relief in the control group was evanescent, commencing dur-

TABle 1. Patient demographics

\begin{tabular}{lcl}
\hline & $\begin{array}{c}\text { Verapamil }+ \\
\text { Dexamethasone }\end{array}$ & Lidocaine \\
\hline $\begin{array}{l}\text { Median pt age (IQR) } \\
\text { No. etiology: }\end{array}$ & $62(11)$ & $61.5(10)$ \\
$\quad$ Nontraumatic & 26 & 26 \\
$\quad$ Traumatic & 11 & 10 \\
No. stage: & & \\
$\quad$ Fibrous & 23 & 23 \\
$\quad$ Calcific & 14 & 13 \\
No. pain at rest: & & 25 \\
Yes & 24 & 11 \\
No & 13 &
\end{tabular}


TABLE 2. Treatment efficacy

\begin{tabular}{|c|c|c|c|c|c|c|c|}
\hline & \multicolumn{3}{|c|}{ Verapamil + Dexamethasone } & \multicolumn{4}{|c|}{ Lidocaine } \\
\hline & Before & After & $\mathrm{p}$ Value & Before & After & $\begin{array}{c}\mathrm{p} \text { Value } \\
\text { (Wilcoxon signed } \\
\text { rank test) }\end{array}$ & $\begin{array}{l}\text { p Value Among } \\
\text { Groups (Mann- } \\
\text { Whitney- } \\
\text { Wilcoxon rank } \\
\text { sum test) }\end{array}$ \\
\hline Median $\mathrm{mm}^{3}$ plaque vol (IQR) & $824.4(986.7)$ & $347.7(421.7)$ & $<0.0001$ & $771.4(630.0)$ & $766.6(692.5)$ & 0.167 & $<0.0001$ \\
\hline $\begin{array}{l}\text { Median degrees penile } \\
\text { deviation (IQR) }\end{array}$ & $43.0(21.5)$ & $21.0(21.0)$ & $<0.0001$ & $41.0(22.5)$ & $41.0(23.0)$ & 0.433 & $<0.0001$ \\
\hline $\begin{array}{l}\text { Range penile deviation } \\
\text { (degrees) }\end{array}$ & $28-73$ & $2-69$ & & $25-70$ & $17-71$ & & \\
\hline No. pain on erection: & & & & & & & \\
\hline None & 0 & 28 & & 0 & 4 & & \\
\hline Mild & 9 & 7 & $<0.0001$ & 12 & 8 & 0.046 & \\
\hline Moderate & 28 & 2 & & 24 & 24 & & \\
\hline
\end{tabular}

ing treatment and lasting 9 to 15 hours in all patients. Pain relief in the study group usually commenced during treatment and endured, lasting throughout the study and thereafter. Partly as a consequence erectile activity (the 2 groups were comparable at the beginning of the study) was regained in $11 \%$ of patients in the control group and in $51 \%$ of the study group. Transient erythema at the site of the electrodes occurred in all patients. There were no other adverse effects.

\section{DISCUSSION}

In this prospective, randomized study transdermal electromotive administration of verapamil and dexamethasone significantly improved objective measurements and subjective symptoms of Peyronie's disease. The treatment is painless, safe and effective, yet 23 patients (24\%) withdrew before completing the study. The reasons are obvious in that 4 outpatient visits per week for 6 consecutive weeks disrupt lifestyles to a considerable degree and the procedures themselves are tedious for all concerned. Although our experience is limited it seems likely that these problems can be solved by introducing several steps. Treatments should be terminated by the end of the first week in patients who do not experience substantial pain relief or who demonstrate no objective improvement after 3 weeks. In addition, most patients can be trained for home treatments, which is a satisfactory resolution for all concerned. Of the patients in these studies $8(22 \%)$ followed this procedure.

Use of verapamil for the treatment of Peyronie's disease has a solid scientific basis ${ }^{10,11}$ and accelerated electromotive delivery is a consequence of electrical repulsion between the anode and positively charged verapamil ions. ${ }^{12}$ The use of dexamethasone rests on occasional case reports ${ }^{13,14}$ and the effectiveness of the verapamil-dexamethasone combination in 3 uncontrolled studies. ${ }^{6-8}$ Its mode of electromotive administration is unusual. Supplied as the ester, dexamethasone bears a weak negative charge whose electrical attraction toward the anode is superseded by an electro-osmotic flow of water accompanying the flux of positively charged ions (verapamil) away from the anode and transporting dexamethasone against its coulombic gradient, solvent drag. ${ }^{15}$ Electric current readily accelerates transdermal administration of lidocaine ${ }^{12}$ and this agent was used in the control group because, like verapamil, it is a vasodilator, and its local anesthetic action provides pain relief during and immediately after treatment. Thus, the potentially confounding factors of vasodilatation which improved blood supply associated with administration of verapamil/dexamethasone are eliminated.

Although noninvasive intraplaque administration of combination "anti-collagen"/anti-inflammatory drugs resulted in significant improvement in patients with Peyronie's disease, there were some unexplained features. About 30\% of the study group showed a poor or absent objective response, yet their disease had no distinguishing characteristics. In addition, the decrease in measurable plaque volume of responders was prompt, which was not the case in patients treated with intralesional injections. ${ }^{3}$ Nevertheless, these issues are minor compared to results recently presented.

At the American Urological Association 2003 annual meeting 2 investigators reported on prospective controlled studies for treatment of the disease. ${ }^{16,17}$ One described intralesional electromotive administration of verapamil and the other discussed intralesional injections of interferon. Both reported objective improvement of curvature in their control arms using $0.9 \% \mathrm{NaCl}$ as placebo with $50 \%$ of patients in the electromotive group and $39 \%$ in the injection group, which easily exceeded remission rates of $29 \%, 13 \%$ and $7 \%$ reported for the natural history of the disease..$^{18-20}$ It can be (and was) argued that the patient population in the electromotive study is as yet too small, but the same restriction does not apply to the injection study whose numbers were adequate.

These unexpected findings elicited a suggestion that energetic interference-electric current or multiple injectionssomehow arrested and/or reversed the disease process. If so, this suggestion does not explain the results in our control group which demonstrated no significant improvement. Obviously, these and other studies must be pursued with particular attention directed toward placebo agents. A localized pharmacological action caused by $\mathrm{NaCl}$ per se is almost impossible to conceive. But an agent such as lidocaine exhibits membrane stabilizing properties, which may interact or interfere with tissue remodeling processes. There are other possibilities and, at present, the only firm conclusion to be drawn is that investigators dealing with Peyronie's disease must recognize the need for further investigations into this surprisingly complex disorder.

\section{CONCLUSIONS}

Intraplaque electromotive administration of verapamil and dexamethasone for Peyronie's disease is a safe and effective treatment that induces significant decreases in penile curvature and plaque volume, and a durable decrease in the level of pain. In contrast, electromotive administration of lidocaine resulted in transient pain relief only.

Physion Srl (Medolla, Italy) donated the electromotive equipment.

\section{REFERENCES}

1. Gholami, S. S. and Lue, T. F.: Peyronie's disease. Urol Clin North Am, 28: 377, 2001

2. Hellstrom, W. J. and Bivalacqua, T. J.: Peyronie's disease: etiology, medical, and surgical therapy. J Androl, 21: 347, 2000

3. Levine, L. A., Goldman, K. E. and Greenfield, J. M.: Experience with intraplaque injection of verapamil for Peyronie's disease. J Urol, 168: 621, 2002 
4. Mulhall, J. P., Badwan, K., Martin, D. and Parker, M.: Does transdermal verapamil applied to the penis infiltrate the tunica albuginea? J Urol, suppl., 167: 205, abstract 826, 2002

5. Levine, L. A., Estrada, C. R., Shou, W. and Cole, A.: Tunica albuginea tissue analysis after electromotive drug administration. J Urol, 169: 1775, 2003

6. Riedl, C. R., Plas, E., Engelhardt, P., Daha, K. and Pflüger, H.: Iontophoresis for treatment of Peyronie's disease. J Urol, 163: 95, 2000

7. Montorsi, F., Salonia, A., Guazzino, G., Barbieri, L., Colombo, R., Brausi, M. et al: Transdermal electromotive multi-drug administration for Peyronie's disease: preliminary results. J Androl, 21: 85, 2000

8. Di Stasi, S. M., Giannantoni, A., Capelli, G., Jannini, E. A., Virgili, G., Storti, L. et al: Transdermal electromotive administration of verapamil and dexamethasone for Peyronie's disease. BJU Int, 91: 825, 2003

9. Kelami, A.: Classification of congenital and acquired penile deviation. Urol Int, 38: 229, 1983

10. Roth, M., Eickelberg, O., Kohler, E., Erne, P. and Block, L. H.: $\mathrm{Ca} 2+$ channel blockers modulate metabolism of collagens within the extracellular matrix. Proc Natl Acad Sci USA, 93: 5478,1996

11. Anderson, M. S., Shankey, T. V., Lubrano, T. and Mulhall, J. P.: Inhibition of Peyronie's plaque fibroblast proliferation by biologic agents. Int J Impot Res, suppl., 12: S25, 2000

12. Banga, A. K. and Chien, Y. W.: Iontophoretic delivery of drugs: fundamentals, developments and biomedical applications. J
Controlled Release, 7: 1, 1988

13. Rothfield, S. H. and Murray, W.: The treatment of Peyronie's disease by iontophoresis of $\mathrm{C}_{21}$ esterified glucocorticoids. J Urol, 97: 874, 1967

14. Fishman, I. J., Wong, H. Y. and Griffith, D. P.: Case report. Iontophoretic delivery of steroids in the treatment of Peyronie's disease: case reports of three successful outcomes. Minim Invasive Ther, 3: 995, 1994

15. Petelenz, T. J., Buttke, J. A., Bonds, C., Lloyd, L. B., Beck, J. E., Stephen, R. L. et al: Iontophoresis of dexamethasone: laboratory studies. J Controlled Release, 7: 141, 1992

16. Levine, L. A. and Sevier, V. L.: A double-blind, placebocontrolled trial of electromotive drug administration (EMDA) using verapamil vs. saline for Peyronie's disease: preliminary results. J Urol, suppl., 169: 274, abstract 1066, 2003

17. Hellstrom, W., Eichelberg, C., Pryor, J. L., Hakim, L. S., Templeton, L., Venable, D. et al: A single-blind, multi-center, placebo-controlled study to assess the safety and efficacy of intralesional interferon alpha-2B in the non-surgical treatment of Peyronie's disease. J Urol, suppl., 169: 274, abstract 1065,2003

18. Williams, J. L. and Thomas, G. G.: The natural history of Peyronie's disease. J Urol, 108: 75, 1970

19. Gelbard, M. K., Dorey, F. and James, K.: The natural history of Peyronie's disease. J Urol, 144: 1376, 1990

20. Kadioglu, A., Tefekli, A., Sanly, O., Kandýralý, E., Tunc, M. and Tellaloolu, S.: Lessons learned from 307 men with Peyronie's disease. J Urol, suppl., 165: 202, abstract 838, 2001 